() (1) https://creativecommons.org/licenses/by/4.0/

ARTIGO

\title{
SABERES E IDENTIDADE DOCENTE: UMA ANÁLISE EM UM CURSO DE LICENCIATURA EM CIÊNCIAS BIOLÓGICAS
}

\author{
MARCOS VINICIUS MARQUES DA SILVA ${ }^{1}$ \\ ORCID: https://orcid.org/0000-0001-6009-3729 \\ KARLA JEANE COQUEIRO BEZERRA SOARES ${ }^{2}$ \\ ORCID: https://orcid.org/0000-0001-5855-8259 \\ MARIANA GUELERO DO VALLE ${ }^{3}$ \\ ORCID: https://orcid.org/0000-0001-5203-370X
}

\begin{abstract}
RESUMO: O presente artigo teve por objetivo analisar a mobilização de saberes docentes e o processo de construção da identidade docente de alunos de um curso de Licenciatura em Ciências Biológicas. Para tanto, foram realizadas entrevistas semiestruturadas com seis licenciandos em fase de conclusão do referido curso. As entrevistas foram gravadas em áudio e posteriormente transcritas e analisadas por meio de uma abordagem qualitativa, utilizando-se o método hermenêutico-dialético. Por meio desta análise emergiram duas categorias, a citar: Espaços de (re)construção e mobilização de saberes e Sentir-se professor: identidades profissionais em construção. Os resultados demonstraram a construção e mobilização de uma série de saberes inerentes à profissão docente que, por sua vez, carregam traços da identidade docente dos licenciandos. Ademais, revelaram que esta identidade é mutável, construída de forma coletiva, depende do reconhecimento de outros atores sociais envolvidos neste processo para que seja assumida e está pautada principalmente em dois saberes: os disciplinares e os experienciais.
\end{abstract}

Palavras-chave: formação de professores, saberes docentes, identidade docente.

\section{KNOWLEDGES AND TEACHING IDENTITY: AN ANALYSIS IN A BACHELOR DEGREE COURSE IN BIOLOGICAL SCIENCES}

\footnotetext{
ABSTRACT: This paper aimed to analyze the mobilization of teaching knowledge and the process of building the teaching identity of students in a Bachelor's Degree course in Biological Sciences. To do so, semi-structured interviews were conducted with six undergraduate students finishing the course. The interviews were audio recorded and later transcribed and analyzed through a qualitative approach, using

${ }^{1}$ Universidade Federal do Maranhão (UFMA). São Luís, MA, Brasil. <marcos.marques@discente.ufma.br>

${ }^{2}$ Universidade Federal do Maranhão (UFMA). São Luís, MA, Brasil. <karla.jeane@ufma.br>.

${ }^{3}$ Universidade Federal do Maranhão (UFMA). São Luís, MA, Brasil. <mariana.valle@ufma.br>. Educação em Revista|Belo Horizonte|v.37|e26209|2021
} 
the hermeneutic-dialectic method. Through this analysis two categories emerged: Spaces of (re)construction and mobilization of knowledge and Feeling like a teacher: professional identities under construction. The results showed the construction and mobilization of a series of knowledges inherent to the teaching profession that, in turn, carry traces of the students' teaching identity. Moreover, they revealed that this identity is changeable, collectively built, depends on the recognition of other social actors involved in this process for it to be assumed and is based mainly on two types of knowledge: the disciplinary and the experiential.

Keywords: teacher education, teacher knowledge, teacher identity.

\section{CONOCIMIENTO E IDENTIDAD DOCENTE: ANÁLISIS EN UN CURSO DE PROFESORADO EN CIENCIAS BIOLÓGICAS}

RESÚMEN: Este artículo tuvo como objetivo analizar la movilización del conocimiento docente y la construcción de la identidad profesional de los estudiantes de una carrera de Licenciatura en Ciencias Biológicas. Para ello, se realizaron entrevistas semiestructuradas a seis estudiantes en la fase de conclusión de dicho curso. Las entrevistas fueron grabadas en audio y posteriormente transcritas y analizadas con un enfoque cualitativo, utilizando el método hermenéutico-dialéctico. A través de este análisis surgieron dos categorías, a mencionar: Espacios de (re)construcción y movilización del conocimiento y Sentirse docente: identidades profesionales en construcción. Los resultados evidencian la construcción y movilización de una serie de conocimientos inherentes a la profesión docente, que, a su vez, llevan huellas de la identidad profesional de los egresados. Además, revelan que esta identidad es mutable, construida colectivamente, depende del reconocimiento de otros actores sociales para que se asuma y se fundamenta principalmente en dos tipos de saberes: disciplinarios y vivenciales.

Palabras clave: formación de profesores, enseñanza del conocimiento, identidad docente. 


\section{INTRODUÇÃO}

A formação de professores tem-se consolidado como objeto de pesquisa acadêmica no Brasil e se constituído como foco de políticas educacionais em virtude do importante papel desempenhado pelos professores na educação. Nesse contexto, surge a necessidade de revisão da formação desses profissionais, visando a superação de modelos formativos que colocam o professor como um mero técnico reprodutor de conhecimentos, e a docência como um ofício desprovido de saberes (GAUTHIER et al., 2013).

As novas perspectivas para a formação de professores defendem que ensinar vai muito além de apenas conhecer o conteúdo ou repassar conhecimentos. Nesse sentido, afirmam a existência de um repertório de saberes próprios e específicos da profissão docente que a diferencia das demais profissões e confere ao professor maior competência para o exercício de sua prática (GUIMARÃES, 2004).

Frente à diversidade de pesquisas que discutem os saberes inerentes à profissão docente, Puentes, Aquino e Quillici (2009) identificaram diferentes nomenclaturas que fazem referência a esses saberes. Dentre estas, destacam-se as ideias de saberes (PIMENTA, 1999; FREIRE, 1996; CUNHA, 2004; GAUTHIER et al., 2013; TARDIF, 2014), conhecimentos (SHULMAN, 1986; GARCÍA 1992) e competências necessárias à docência (MASETTO, 1998; BRASLAVSKY, 1999; PERRENOUD, 2000).

Os autores afirmam que, embora seja representado por diferentes termos, o significado conceitual para o conjunto de capacidades sistematizadas necessárias ao exercício da docência assemelhase em todos os trabalhos analisados. Campelo (2001) também destaca que, embora haja essa diversidade de nomenclaturas para designar os saberes dos professores, os estudos que abordam esta temática compartilham dos mesmos objetivos: contribuir para a construção e o reconhecimento da identidade docente e formar professores que desenvolvam um ensino coerente com os fins socialmente estabelecidos para a educação.

No presente trabalho, assumiremos a concepção de "saber" que, na perspectiva de Tardif (2014, p. 60), envolve "os conhecimentos, as habilidades (ou aptidões) e as atitudes docentes [...]". Este mesmo autor situa os saberes docentes na interface entre o individual e o social. Ademais, ressalta que, embora a existência desses saberes dependa dos professores, que de forma individual estão empenhados em uma prática, esses saberes são também sociais, pois são compartilhados por indivíduos que possuem uma mesma formação e produzidos mediante relações estabelecidas entre diferentes grupos.

Nesse sentido, ainda na perspectiva do referido autor, é no trabalho cotidiano, em meio às adversidades da profissão, que os professores avaliam e ressignificam os saberes adquiridos ao longo de suas histórias de vida e formação profissional, desenvolvendo um saber composto por diferentes saberes, advindos de variadas fontes, por meio dos quais eles compreendem e dominam sua prática. Assim, Tardif (2014, p. 36) define o saber docente como "um saber plural, formado pelo amálgama, mais ou menos coerente, de saberes oriundos da formação profissional e de saberes disciplinares, curriculares e experienciais".

Para Pimenta (1999), os saberes ligados à experiência são os que ganharam menor destaque na formação inicial de professores, sendo necessário conferir a eles um estatuto epistemológico, uma vez que a mobilização destes saberes constitui o primeiro passo para o processo de construção da identidade docente. A autora ressalta que, considerando a prática docente e os saberes que ela produz, será possível superar a tradicional fragmentação dos saberes da docência e ressignificá-los no processo de formação de professores, à medida que o futuro profissional possa constituir o seu saber-fazer a partir de seu próprio fazer.

Nesta perspectiva, é necessário que os cursos de licenciatura criem possibilidades para que seus alunos desenvolvam conhecimentos, habilidades, atitudes e valores que os auxiliem a construir um saber-ser e um saber-fazer que correspondam aos desafios colocados pelo ensino enquanto prática social (PIMENTA, 1999). O Estágio Supervisionado surge, nesse contexto, como um importante componente curricular em que, por meio de reflexões sobre suas práticas, esses estudantes poderão desenvolver seus saberes docentes em um processo constante de construção de suas identidades profissionais (PIMENTA, 1999; PIMENTA; LIMA, 2012).

Guimarães (2004) aponta que a temática da identidade é complexa e possui significados distintos, a depender da ótica sob a qual é analisada. Entretanto, apesar de multifacetada, os teóricos que 
se dedicam a estudá-la concordam em um mesmo ponto: a identidade é um processo que se constrói ao longo do tempo e está sujeita a constantes transformações (CIAMPA, 1987; HALL, 2000; SILVA, 2007). Corroborando com essa ideia, Dubar (1997, p. 13) argumenta que a identidade:

[...] não é dada, de uma vez por todas, no ato do nascimento: constrói-se na infância e deve reconstruir-se sempre ao longo da vida. O indivíduo nunca constrói sozinho: depende tanto dos julgamentos dos outros, como das suas próprias orientações e auto definições. A identidade é produto de sucessivas socializações.

A identidade, nesse sentido, é individual, mas, ao mesmo tempo, coletiva, pois é construída no seio das relações sociais e depende do reconhecimento e da confirmação do outro para que seja assumida. Por ser construída socialmente, pode mudar de acordo com as modificações sociais sofridas pelos grupos tidos como referência, à medida que estes alteram as suas expectativas, valores e configurações identitárias (SANTOS, 2002). Entende-se, portanto, que a identidade não é fixa ou permanente, mas um processo que se desenvolve entre o intersubjetivo, caracterizando-se como um fenômeno gradativo, que ocorre a partir de interpretações feitas sobre si mesmo, enquanto indivíduo inserido em um determinado contexto social, e pode ser entendida como uma resposta à pergunta "quem sou eu neste momento?" (MARCELO, 2009, p. 112).

Ao discutir mais especificamente sobre a identidade docente, Pimenta (1999, p. 5) aponta que esta:

[...] se constrói, pois, a partir da significação social da profissão, da revisão constante dos significados sociais da profissão, da revisão das tradições [...] Constrói-se, também, pelos significados que cada professor, enquanto ator e autor, confere à atividade docente em seu cotidiano a partir de seus valores, de seu modo de situar-se no mundo, de sua história de vida, de suas representações, de seus saberes, de suas angústias e anseios, do sentido que tem em sua vida o ser professor. Assim como a partir de sua rede de relações com outros professores, nas escolas, nos sindicatos e em outros agrupamentos.

Dessa forma, a identidade profissional docente pode ser definida por meio de como a profissão é representada socialmente e das relações sociointerativas estabelecidas entre os professores e seus alunos, as famílias, seu ambiente de trabalho, bem como com as pessoas com as quais convivem no cotidiano e que possam, de alguma forma, contribuir para a (re)construção de sua identidade docente identidade esta que não é fixa ou acabada, mas que está sujeita a sucessivas ressignificações.

Nessa perspectiva, entendemos que a busca e o desenvolvimento da identidade profissional podem ser propiciados pelos saberes docentes, e que tanto estes saberes quanto o reconhecimento desta identidade constituem a profissionalidade docente e são essenciais para sua profissionalização (GUIMARÃES, 2004; CUNHA, 2007). Assim, identificar a natureza desses saberes e a identidade profissional que eles podem gestar torna-se pertinente no sentido de que pode trazer contribuições para a valorização da profissão docente não apenas no âmbito epistemológico, mas também no campo político e social, com vistas a uma formação de professores comprometidos com o processo de ensinoaprendizagem em seu sentido mais amplo, ultrapassando as concepções tradicionais de professores como meros técnicos reprodutores de conhecimentos. Desse modo, o presente trabalho teve por objetivo analisar a construção e mobilização dos saberes docentes no processo de construção da identidade profissional de alunos de um curso de Licenciatura em Ciências Biológicas.

\section{PERCURSO METODOLÓGICO}

A pesquisa foi desenvolvida por meio de uma abordagem qualitativa (BOGDAN; BIKLEN, 2007) e realizada no contexto de um curso de Licenciatura em Ciências Biológicas de uma Instituição de Ensino Superior (IES) pública situada na região nordeste brasileira. Participaram da investigação seis licenciandos em fase de conclusão do referido curso, tendo como critério de seleção o fato de estarem matriculados no Estágio Supervisionado II, componente curricular que integra o último semestre do curso investigado. Isso pressupõe que tais estudantes já haviam cursado a maioria das disciplinas e 
vivenciado o máximo de experiências que o curso poderia proporcionar, como a participação em laboratórios, grupos de pesquisa, eventos, projetos e programas de ensino, pesquisa e/ou extensão etc.

Os dados foram coletados após a assinatura do Termo de Consentimento Livre e Esclarecido - TCLE - e por meio de entrevistas semiestruturadas (LÜDKE; ANDRÉ, 1986). O roteiro das entrevistas contemplou perguntas acerca do percurso formativo dos licenciandos e de suas experiências ao longo do curso. Suas identidades foram preservadas mediante a utilização de nomes fictícios. O tratamento dos dados obtidos foi realizado por meio do método hermenêutico-dialético, o qual permite ampla compreensão do discurso dos participantes da pesquisa à medida que o situamos em seus contextos de produção (MINAYO, 2010).

O método proposto por Minayo (2010) envolve três etapas, a citar: ordenação dos dados, classificação dos dados e análise final. A etapa de ordenação dos dados corresponde ao mapeamento do material obtido e à constituição do corpus da pesquisa. Nessa etapa, foi realizada a transcrição dos áudios das entrevistas por meio da qual pudemos identificar e selecionar os trechos mais representativos de acordo com o objetivo geral da presente investigação.

Na segunda etapa - classificação dos dados -, Minayo (2010) ressalta a importância da compreensão de que os dados não existem por si só; eles são construídos à medida que são submetidos a questionamentos com base na fundamentação teórica da pesquisa. Desse modo, identificamos recorrências, convergências e divergências entre os discursos dos licenciandos que nos levaram à construção de duas categorias, a saber: "Espaços de (re)construção e mobilização de saberes", em que identificamos espaços nos quais os licenciandos mobilizaram com maior expressividade os saberes construídos ao longo do processo formativo; e "Sentir-se professor: identidades profissionais em construção", na qual foram abordados, na perspectiva dos licenciandos, aspectos constitutivos de suas identidades docentes.

Após a fase de categorização, partimos para a última etapa do método proposto por Minayo (2010), denominada análise final. Nesta etapa foi realizada a articulação entre os dados obtidos e os referenciais teóricos que fundamentaram a investigação. Para a análise dos saberes docentes, utilizamos Tardif (2014), que os classifica como: Saberes da formação profissional - conhecimentos das ciências da educação e concepções provenientes de reflexões sobre a prática educativa que orientam a atividade dos professores, fornecendo um pilar à profissão e algumas técnicas e formas de saber-fazer; Saberes disciplinares - saberes definidos, selecionados e transmitidos pelas instituições de formação que, como o próprio nome sugere, se referem às disciplinas que o professor se dedica a lecionar; Saberes curriculares - correspondem aos discursos, objetivos, conteúdos e métodos que a escola utiliza para selecionar e categorizar os conhecimentos historicamente produzidos pela humanidade para elaborar o currículo escolar; e, por fim, Saberes experienciais - saberes produzidos pelos próprios professores por meio das experiências vivenviadas no contexto da atuação profissional.

Os aspectos relacionados à construção da identidade docente foram analisados a partir de Dubar (2009), Guimarães (2004), Pimenta (1999) e Tardif (2014), que discutem a temática da identidade de forma direta ou indireta, entendendo-a como um processo que se desenvolve em um contexto social por meio de relações intersubjetivas e que está em constante transformação.

\section{RESULTADOS E DISCUSSÃO}

\section{Espaços de (re)construção e mobilização de saberes}

Ao longo da análise dos dados, identificamos diferentes momentos que possibilitaram maiores oportunidades de mobilização de saberes. Dentre estes espaços, destacam-se principalmente o Estágio Supervisionado e o Programa Institucional de Bolsas de Iniciação à Docência - PIBID. Dessa forma, dividimos esta seção em duas subseções nas quais abordamos os saberes construídos, mobilizados e/ou ressignificados pelos licenciandos em cada um desses espaços.

\section{O Programa Institucional de Bolsas de Iniciação à Docência}


Criado em 2007 pela Coordenação de Aperfeiçoamento de Pessoal de Nível Superior (CAPES), o Programa Institucional de Bolsas de Iniciação à Docência - PIBID - tem por objetivo inserir os licenciandos desde os primeiros anos da graduação em seu futuro ambiente de trabalho para que possam desenvolver atividades didático-pedagógicas em escolas públicas brasileiras (BRASIL, 2019). Dentre os participantes da pesquisa, duas licenciandas fizeram parte do referido programa e em suas entrevistas apresentaram alguns relatos em que observamos as potencialidades do PIBID na formação inicial de professores e, consequentemente, no processo de construção e mobilização de saberes.

Apesar de vivenciarem o espaço escolar ao longo de suas histórias de vida, por meio do PIBID, as licenciandas começaram a ressignificar este espaço sob outra perspectiva. Durante muito tempo estiveram na condição de alunas, mas, durante a participação no programa, regressaram a este ambiente no papel de professoras. À medida que percebem que os papéis foram mudados, as licenciandas sentem o peso das responsabilidades inerentes à profissão docente e, consequentemente, desenvolvem certos receios no que tange à prática profissional. Entretanto, em meio a esta problemática, o PIBID surge como um agente de superação desses medos, no momento em que possibilita o contato com o ambiente escolar, como pode ser evidenciado no trecho seguinte:

O mais importante que eu posso falar sobre o Pibid é que eu superei vários medos [...] o medo de falar em público, o medo de falar para outras pessoas, eu aprendi a refazer a minha cabeça dentro do Pibid, então foi muito importante essa parte para mim, porque no Pibid a gente ia lá para a escola e tudo mais, a gente teve esse contato de ir lá e eu perdi tudo isso, vi que não era um bicho de sete cabeças (Bruna).

A partir desse trecho, podemos dizer que, de certa forma, o programa alcança um de seus objetivos ao criar possibilidades para o aprimoramento profissional dos futuros professores, que, possivelmente, quando estiverem em exercício, sentirão com menos impacto o "choque do real". Esse choque, como aponta Huberman (2007) ao discutir o ciclo de vida profissional dos professores, constitui um dos aspectos do que é denominado estádio de "sobrevivência", no qual os professores em início de carreira se deparam com a complexidade da situação profissional, evidenciando o distanciamento entre as perspectivas e as realidades cotidianas da sala de aula.

De acordo com Ponte et al. (2001), os primeiros anos da profissão docente são cruciais para o desenvolvimento do conhecimento e da identidade do professor, uma vez que este se encontra entregue a si próprio, tendo que desenvolver estratégias para lidar com uma variedade de papéis profissionais em condições variadas e adversas. Embora situadas em um contexto diferente, por meio do PIBID, as licenciandas têm seus primeiros contatos com a realidade escolar, e esta vivência tem impacto significativo na formação dessas alunas. Por meio das experiências vivenciadas no âmbito deste programa, as licenciandas podem ressignificar concepções sobre a escola, a educação, o currículo, a disciplina, os alunos e a atividade docente, contribuindo para o processo de construção de saberes e de sua identidade docente que possivelmente as auxiliarão no exercício da profissão.

Observamos também que uma das contribuições do PIBID está presente no contexto do planejamento, prática essencial para a organização e sistematização do trabalho docente. De acordo com Padilha (2001), o planejamento compreende um processo que tem por característica evitar a improvisação e visa dar respostas a um determinado problema por meio do estabelecimento de fins e meios que nortearão a ação educativa. Isso pode ser evidenciado na fala de Isabel:

O PIBID me deu muito essa ideia de planejamento, a importância do planejamento, de você pensar "como que eu vou dar essa aula, que atividades eu posso fazer?" Até mesmo a divisão de quantos alunos têm na turma, que atividade eu posso fazer, quanto tempo eu vou me dispor para aquela atividade [...] (Isabel).

Além de auxiliar na superação de possíveis medos relacionados à docência, contribuir no processo de construção de saberes e suscitar a prática do planejamento, o PIBID possibilita a articulação/mobilização entre diferentes saberes docentes construídos, o que pode ser observado na fala que segue: 
No Pibid eu aprendi a escrever para eventos [...] Eu fui para dois congressos [...] Além disso, lá a gente era muito incentivado a planejar aulas diferenciadas, a fazer atividades em que os alunos eram construtores do seu próprio conhecimento, então, por exemplo, o trabalho que eu enviei para um evento, foi sobre os biomas maranhenses, que a gente trabalhou muito a questão do regionalismo, porque nos livros didáticos falam de biomas, mas não os daqui, e aqui tem bastante. Era sobre uma trilha sensitiva, que a gente levou vários materiais que eles pudessem cheirar, ouvir, até sentir mesmo comendo, então foi muito legal (Isabel).

Por meio dos saberes da formação profissional e pedagógicos, a licencianda propõe uma aula em que coloca seus alunos como protagonistas no processo de aprendizagem e, para desenvolvê-la, utiliza-se dos saberes disciplinares, por meio dos quais consegue identificar os diferentes biomas que compõem o seu estado. Por meio dos saberes curriculares, questiona o programa escolar, que na maioria das vezes segue apenas o livro didático, e, a partir disso, insere as particularidades regionais do contexto em que está inserida para que o ensino se torne mais representativo e significativo aos alunos.

Um aspecto ainda mais interessante evidenciado nesse relato é que os resultados dessa atividade não se limitaram à sala de aula: a licencianda ultrapassou os muros da escola, levando o trabalho desenvolvido a eventos da área, nos quais pôde compartilhar a experiência vivenciada com outros professores e suscitar o desenvolvimento de práticas semelhantes a essa, o que representaria um indício do desenvolvimento de habilidades de pesquisa e investigação sobre a própria prática, processos por meio dos quais novos saberes podem ser produzidos (SCHÖN, 1992).

Ao discutir sobre o professor-pesquisador como instrumento de melhoria do ensino de Ciências, Moreira (1989) aponta que o pesquisador em ensino é, na maioria das vezes, alguém exterior à sala de aula e que os resultados das pesquisas atingem apenas outros pesquisadores e não chegam às escolas. Em meio a esta problemática, o autor destaca a necessidade de engajar os professores em atividades de pesquisa, uma vez que, por estarem em constante contato com a realidade escolar, tais profissionais estariam em melhor posição para desenvolvê-la, o que poderia tornar os resultados dessas pesquisas mais significativos para fundamentar suas práticas.

De acordo com Nunes (2008), a pesquisa deve ser a base da formação docente, pois pode possibilitar a esses profissionais o desenvolvimento de uma consciência crítica sobre suas ações. $\mathrm{Na}$ perspectiva da autora, essa prática propiciaria a formulação de questões de pesquisa condizentes com o contexto da sala de aula. Assim, os professores assumiriam maior responsabilidade sobre suas decisões pedagógicas, pois, baseados em resultados empíricos, estariam mais capacitados para identificar sob quais condições as estratégias didáticas adotadas alcançariam melhores resultados.

\section{O Estágio Supervisionado}

No contexto analisado, o Estágio Supervisionado é dividido em Estágios I e II, desenvolvidos no Ensino Fundamental e Ensino Médio, respectivamente. Todos os participantes haviam concluído o Estágio I no semestre anterior à coleta de dados desta pesquisa e estavam concluindo a fase de regência de aulas do Estágio II. Nossos resultados condizem com o que é apontado pela literatura, que evidencia as contribuições do Estágio Supervisionado para a construção e mobilização de uma série de saberes ligados ao trabalho docente (BACCON; ARRUDA, 2010; MARTINY; SILVA, 2011; CARMO; ROCHA, 2016), uma vez que pode possibilitar a reflexão sobre a ação profissional, além de proporcionar o desenvolvimento de uma visão crítica sobre a dinâmica das relações existentes no futuro ambiente de trabalho (BURIOLLA, 1995; PIMENTA; LIMA, 2012).

Ao chegarem aos estágios, alguns licenciandos relataram as dificuldades encontradas durante o desenvolvimento de suas ações. Isso pode ser evidenciado na seguinte fala:

(o curso) Não me preparou tanto, tem disciplinas que a gente vê muitas coisas teóricas e na prática a gente não consegue associar isso para sala de aula, eu acho que é muito voltado para teoria e não para nossa sala de aula [...] (Samara). 
O discurso de Samara revela as fragilidades de sua formação, que se assemelha à encontrada em outros cursos de formação de professores, os quais, na maioria das vezes, constroem seus currículos com base em disciplinas que, quando isoladas entre si, não evidenciam os nexos com a realidade do cotidiano escolar, o que recorrentemente é confirmado pelo discurso de que "na prática a teoria é outra" (PIMENTA; LIMA, 2012)

Ao reconhecerem as limitações decorrentes das falhas presentes no processo formativo, os licenciandos tentam desenvolver, por meio das experiências proporcionadas pelo estágio, um saber que fundamente suas ações de forma mais significativa. Durante esse processo, aproximam-se do que Pimenta e Lima (2012) chamam de "prática como imitação de modelos", na qual a aprendizagem da profissão se dá por meio da observação, reprodução ou reelaboração das práticas observadas.

As autoras salientam que durante esse processo os alunos são capazes de elaborar o seu modo de ser/agir a partir da análise crítica das ações dos professores com quem convivem. Nesse processo de construção do seu "eu" como professor, os alunos adaptam, separam e/ou acrescentam o que lhes parece ser mais relevante, utilizando-se de suas experiências e saberes adquiridos ao longo do tempo. Isto pode ser evidenciado, como veremos no próximo trecho, quando Samara relata que durante seu estágio tentou fazer tudo diferente do que era feito pelo seu professor supervisor:

Eu fiz um jogo sobre plantas, que era de perguntas e respostas, fiz paródias para explicar sobre o ciclo reprodutivo das plantas [...] Eu percebi que era o que chamava atenção deles, porque o meu supervisor técnico, que era muito rígido, o negócio dele era chegar na sala de aula, escrever no quadro, explicar e pronto, acabou [...]. E aí eu percebi que alguns alunos, se identificavam melhor com esses outros tipos de atividades [...] coisas que eles não faziam com professor, então eu fiz tudo que o professor não fazia. (Samara).

Ao realizar esse exercício de moldar sua prática em contraposição à do seu supervisor, inferese que Samara começa a mobilizar seus saberes da experiência, que são "aqueles que os professores produzem no seu cotidiano docente, num processo permanente de reflexão sobre sua prática, mediatizada pela de outrem" (PIMENTA, 1999, p. 20). Nomeados por Tardif (2014, p. 39) como saberes experienciais, estes saberes "brotam da experiência e são por ela validados. Eles incorporam-se à experiência individual e coletiva sob a forma de habitus e de habilidades de saber-fazer e de saber-ser".

Além de possibilitar a construção desses saberes, a prática cotidiana da profissão também oportuniza a ressignificação dos saberes oriundos das instituições de formação (PIMENTA, 1999; TARDIF, 2014). Percebemos que os licenciandos chegam aos estágios carregados de saberes disciplinares, curriculares e pedagógicos obtidos ao longo do processo formativo que, de certa forma, lhes possibilitam a construção de determinadas certezas sobre a profissão. Eles estudam as tendências pedagógicas, as metodologias e estratégias de ensino e, ao longo do estágio, tentam aplicar essas técnicas, o que pode ser observado na próxima fala:

No Estágio I eu usei de muita prática assim mostrando coisas do cotidiano deles, associando com a aula [...] eu tentei levar um pouco disso para o Estágio II, só que eu vi que os alunos brincavam muito em vez de prestar atenção, e aí eu tentei reduzir no máximo que eu podia, tanto que eu fiz apenas duas práticas, mas aí eu fiz outros tipos de atividades (Samara).

Observamos que, ao analisarem e refletirem sobre seu contexto, os licenciandos percebem quais estratégias são pertinentes ou não àquele momento e, a partir disso, buscam estabelecer outras alternativas. Desse modo, a experiência cotidiana pode ser vista como um processo de aprendizagem por meio do qual os professores retraduzem sua formação e a adaptam à profissão, reformulando o que não lhes for pertinente e mantendo o que puder servir para sua prática (TARDIF, 2014).

Os relatos dos licenciandos remetem, portanto, ao que, na perspectiva de Tardif (2014), representa um processo de retroalimentação de saberes por meio do qual os futuros professores retomam criticamente os saberes construídos antes ou fora da prática profissional. Por meio da experiência, esses saberes são revisados, julgados e selecionados pelos professores, visando a construção de um saber formado por todos os outros saberes retraduzidos e que serão validados pela prática cotidiana. Esse 
processo também pode ser observado no trecho seguinte, no qual Bruna relata as medidas tomadas a partir do momento em que percebe as peculiaridades de sua turma do Estágio II:

[...] eu tinha uma turma muito agitada e a gente teve que fazer acordo com eles. Então eu pedi para eles fazerem perguntas sobre a vida, sobre ciências. Essas perguntas eram colocadas dentro de uma sacolinha e se eles deixassem eu dar aula de boa a gente respondia às perguntas no final da outra aula. Eu vi que com o tempo eles foram aceitando o acordo muito bem [...] então foi muito legal mesmo, isso aí foi dica do meu supervisor docente [...] (Bruna)

A partir do relato de Bruna, no qual se destaca a importante participação do professor supervisor que, ao aconselhá-la, a ajuda a contornar a situação apresentada, podemos evidenciar o caráter interativo do saber experiencial, que se constitui como um saber que não reside em sua totalidade em certezas subjetivas individuais, mas que se configura como um saber partilhado que emerge, também, das relações estabelecidas entre os professores que, cotidianamente, compartilham entre si um saber prático baseado em suas experiências (TARDIF, 2014). Tais saberes emergem, também, das relações estabelecidas entre os futuros professores e seus alunos e do confronto às adversidades que a prática cotidiana lhes impõe. Sobre essas adversidades, Luiza conta que:

[...] um aluno disse que não ia fazer a atividade. Eu o chamei para conversar e ele veio pra cima de mim, dizendo que não queria nada daquilo, que aquilo não ia fazer diferença na vida dele, que ele não queria mais estudar. Nesse momento eu percebi que o problema dele não era comigo, era alguma coisa que ele estava passando [...] Depois eu conversei com a professora e ela falou que ele tinha problema com a família [...] então nessa situação eu falei com o pai, depois eu conversei direitinho com o menino, ele me pediu desculpa e eu dei outra oportunidade pra ele fazer a atividade [...] eu não deixei aquele episódio ser uma barreira tanto para mim quanto para ele (Luiza).

Embora desconfortável, de certa forma, essa situação torna-se formadora, uma vez que, por meio dela, Luiza possivelmente poderá fazer reflexões que a guiarão em situações futuras que se assemelhem a esta. Ademais, esse relato leva-nos a observar a natureza social do saber docente, que é construído, também, por meio das complexas relações que o professor estabelece com seus alunos.

Segundo Tardif (2014, p. 50), o ensino enquanto prática social implica o estabelecimento de "uma rede de interações com outras pessoas num contexto onde o elemento humano é determinante e dominante e onde estão presentes símbolos, valores, sentimentos, atitudes que são passíveis de interpretação e decisão". Ainda na perspectiva do autor, essas interações são mediadas por discursos, comportamentos, maneiras de ser etc. e exigem dos professores não um saber sobre um objeto de conhecimento ou sobre uma prática, mas a capacidade de se comportarem como pessoas em interação com outras pessoas.

Assim como Luiza, Isabel também se depara com uma situação inesperada que suscita reflexões durante o desenvolvimento do Estágio. Tal situação pode ser observada no próximo relato:

[...] eu dei aula sobre cromossomos e aí eu falei sobre DNA, cromatina e cromossomos, tudo isso em uma aula só. Eu dei aula em slides, levei até um colar para explicar cromatina, cromossomo e aí, no início todo mundo gostou, [...] só que era tanto conteúdo, que teve uma hora que eles desistiram [...] era tanta coisa, que no final eles não estavam entendendo mais e aí, quando eu pedi para eles fazerem a paródia, eles não quiseram [...] depois eu entendi que quando a gente coloca assuntos demais, ninguém aguenta. Se eu tivesse parado na hora e só retomado os conteúdos e tentado fazer atividade de uma maneira mais leve, talvez tivesse dado certo [...] Então eu acho que isso é legal, porque a gente reflete sobre o que aconteceu. (Isabel).

As experiências vivenciadas pelas licenciandas situam-se no que Tardif (2014) denomina como condicionantes da profissão. Segundo o autor, esses condicionantes estão relacionados a situações reais do trabalho docente que não são passíveis de definições acabadas e que exigem improvisação e habilidade pessoal para serem enfrentadas. Ainda na perspectiva do autor, lidar com os condicionantes é formador, pois o docente pode desenvolver os habitus (certas disposições adquiridas na e pela prática), que podem "transformar-se num estilo de ensino, em "macetes" da profissão e até mesmo em traços da 
personalidade profissional que se manifestam através de um saber-ser e de um saber-fazer pessoais e profissionais validados pelo trabalho cotidiano" (TARDIF, 2014, p. 49).

Durante esse processo, evidencia-se a importância da reflexão na prática docente. Ao se depararem com os condicionantes da profissão, as licenciandas reconhecem suas limitações, refletem sobre suas ações e, a partir disso, tentam estabelecer estratégias para superar os problemas impostos pela prática cotidiana, aproximando-se de um perfil denominado por alguns autores como professor reflexivo (SCHÖN, 1992; ALARCÃO, 1996). Segundo Pimenta (1999), o professor, enquanto profissional reflexivo, é entendido como intelectual em constante formação - formação esta que pode ser entendida como autoformação, uma vez que os professores reelaboram os saberes iniciais frente às situações vivenciadas nos contextos escolares em um processo contínuo de reflexão na e sobre a prática.

Até aqui abordamos os saberes experienciais como saberes que emergem da prática e situam o trabalho docente quando os licenciandos sentem dificuldade em dar respostas às situações inesperadas da prática cotidiana vivenciada nos estágios, pois estas ultrapassam os saberes da formação profissional. Em decorrência disso, por meio da experiência e reflexão na experiência, estes estudantes constroem uma formação baseada no que alguns autores denominam de epistemologia da prática (SCHÖN, 1992), que valoriza a prática profissional como espaço de construção de saberes por meio da reflexão, análise e problematização dessa prática.

Entretanto, é importante ressaltar que, apesar de práticos, esses saberes não emergem somente da prática. A importância da prática é inegável, o conhecimento vem da prática, mas, ao situálo unicamente neste viés, reduziremos todo saber à sua dimensão prática, excluindo sua dimensão teórica e consequentemente reforçando uma dicotomia entre teoria e prática (GHEDIN, 2006). Segundo Pimenta (2006), o saber docente é nutrido pelas teorias. Estas, por sua vez, dotam os sujeitos de "variados pontos de vista para uma ação contextualizada, oferecendo perspectivas de análise para que os professores compreendam os contextos históricos, sociais, culturais, organizacionais e de si próprios como profissionais" (PIMENTA, 2006, p. 24). Desse modo, fica evidente a importante e necessária articulação entre teoria e prática no processo de construção de saberes durante a formação de professores.

Os espaços aqui abordados oportunizaram a construção, retradução e mobilização de diferentes saberes que auxiliaram os licenciandos no desenvolvimento de suas ações e na compreensão da complexidade que envolve o trabalho docente. Observamos também que estes espaços possibilitaram que eles se posicionassem não mais como alunos, mas como professores, além de fornecerem indícios de que gradativamente constroem suas identidades como docentes com base nesses saberes. Na próxima seção, veremos as implicações dessas experiências proporcionadas por esses espaços e dos diferentes saberes que mobilizaram para o processo de construção da identidade docente desses licenciandos.

\section{Sentir-se professor: identidades profissionais em construção}

$\mathrm{Na}$ tentativa de traçar o percurso do processo de construção da identidade docente, debruçamo-nos, primeiramente, sobre as motivações que levaram os participantes desta pesquisa a optarem pelo curso na modalidade licenciatura. Com exceção de Luiza e Samara, que disseram ter escolhido a licenciatura, percebemos que os demais participantes, a priori, não ingressaram no curso com a intenção de serem professores. Alguns alunos sequer sabiam a diferença entre os cursos de licenciatura e os de bacharelado, e seus discursos sugerem que gostariam de seguir carreira como biólogos.

[...] eu não sabia que em um semestre entra o bacharelado e no outro a licenciatura, eu não sabia que tinha essa divisão [...] eu escolhi biologia, mas não na intenção de dar aula, mas voltado a ser cientista, ficar dentro de um laboratório, eu sempre me via dessa forma (Daniela).

Embora a intenção inicial seja a formação como biólogos, percebemos que, ao longo do curso, os alunos parecem mudar de opinião em relação à licenciatura, às temáticas abordadas em torno da formação docente, e começam a se identificar com esta área, seja por afinidade com as disciplinas, ou por melhores oportunidades no mercado de trabalho. Isso pode ser evidenciado no trecho seguinte: 
[...] hoje em dia eu já percebo que se eu voltasse atrás e pudesse escolher entre licenciatura e bacharelado, eu não escolheria o bacharelado e sim a licenciatura, porque eu acho que é uma coisa que eu gosto, a área da docência. Eu acredito que tenha mais oportunidades no curso de licenciatura e principalmente, porque eu acho que de certa forma eu me encontrei no curso de licenciatura (Mateus).

Durante esse processo de identificação com o curso e com a profissão, os licenciandos relatam alguns elementos que trazem contribuições para sua formação como professores e, consequentemente, para a construção de sua identidade, além de pontuarem os fatores que dificultam essa construção. É importante ressaltar que, dada a complexidade da temática identidade, a identidade docente será tratada aqui mediante o aspecto do desenvolvimento de convicções relacionadas à profissão docente (GUIMARÃES, 2004), abordando-se o papel do curso analisado no sentido de criar possibilidades para que seus licenciandos se identifiquem com a profissão.

Dentre os fatores que, na perspectiva dos licenciandos, contribuem para a construção desta identidade, o Estágio Supervisionado aparece na maioria dos discursos como um divisor de águas no processo de reconhecimento como professor, o que pode ser evidenciado na fala de Bruna:

O meu pensamento em relação à licenciatura mudou drasticamente mesmo quando eu fiz Estágio I, até então, eu aceitava já de boa a licenciatura, só que gostar realmente foi só a partir do estágio. Então esse contato com a escola, com os professores, com os alunos é muito importante e eu acho que só a partir daí é que a gente consegue entender o que é a licenciatura (Bruna).

De acordo com Pimenta (1999), analisar o contexto escolar com o olhar não mais de aluno, mas de futuros professores, é um dos passos a serem seguidos no processo de construção da identidade docente. À medida que o estágio possibilita o contato com o espaço escolar, os alunos começam a construir sua própria forma de ser e estar na profissão, posicionando-se não mais como alunos, mas como professores profissionais que, por meio dos saberes que desenvolveram, percebem que apenas o que foi adquirido durante o processo formativo é insuficiente ou desconexo com a realidade e, assim, retraduzem esses saberes de acordo com o contexto em que estão inseridos. Além do Estágio Supervisionado, notamos que o PIBID também exerce papel fundamental para que os alunos se identifiquem com a profissão:

(O PIBID) me ensinou a valorizar a profissão, me ensinou a gostar e me ensinou a ser professora [...] O PIBID me formou professora e o Estágio I e o Estágio II fizeram eu me encontrar mais ainda na sala de aula [...] (Isabel).

Por meio dos relatos que envolvem tanto os estágios quanto o PIBID, que são momentos que estreitam as relações entre os licenciandos e seu futuro ambiente de trabalho, podemos evidenciar o que é pontuado pela literatura sobre a necessidade de uma epistemologia diferenciada para a formação de professores; esta toma a prática como ponto de partida e de chegada para sua formação, uma vez que o professor gradativamente aprende a dominar seu ambiente de trabalho, à medida que nele se insere e o interioriza, desenvolvendo saberes específicos e necessários à construção de sua identidade frente às incertezas, singularidades e conflitos inerentes à prática profissional por meio da reflexão na e sobre a ação (PIMENTA, 1999; GUIMARÃES, 2004; TARDIF, 2014).

Aspectos relacionados à matriz curricular do curso também são pontuados pelos licenciandos como importantes durante o processo de identificação com a profissão. São destacadas as disciplinas específicas das Ciências Biológicas que lhes conferem uma base de conteúdo, e as disciplinas pedagógicas, que viabilizam o ato de ensinar. Sobre as disciplinas específicas, observamos que, como aponta Pimenta (1999), elas têm forte influência no processo de construção da identidade profissional, constituindo-se, em alguns casos, como fator principal para que esta identidade seja atribuída ao (futuro) professor pelos demais atores sociais com os quais interage. Isso pode ser observado no caso de Daniela, que, ao relatar as contribuições do curso para sua formação como professora, destaca: 
Os assuntos que eu aprendi aqui (no curso), de certa forma [...] vão me ajudar a me construir como professora [...] em questão de ter uma base mesmo de conteúdo, todas as disciplinas que a gente faz no curso, uma questão de base no conhecimento específico (Daniela).

Observamos que Daniela se apoia principalmente nos saberes disciplinares para construir sua identidade como professora. Esse fato está alinhado à forma como a profissão docente é representada socialmente, em que se evidencia o domínio do conteúdo como principal fator para caracterizar o professor. De certa forma, isso traz experiências negativas à Daniela durante o desenvolvimento do Estágio I, pois a licencianda ficou responsável por uma turma de $9^{\circ}$ ano do ensino fundamental e esteve em uma situação em que teve que ministrar conteúdos de química, disciplina da qual, segundo o relato, a licencianda não tinha domínio:

Eu me senti muito insegura, eu ia para o estágio pedindo para acabar, não porque eu não queria ser professora, mas porque eu não tinha jeito com os alunos, porque eu dei aula de química e não de biologia, eu estava dando aula no $9^{\circ}$ ano. Eu me senti muito mal em dar aula no estágio I, porque era um conteúdo que eu não tinha tanta noção, a gente tem a disciplina de química, mas é uma coisa assim muito superficial [...] (Daniela).

Esse fato trouxe implicações diretas ao desenvolvivemnto das relações entre Daniela e a professora que a supervisionava e também com os alunos. No momento em que os alunos percebem as limitações da licencianda em relação ao domínio da disciplina, eles não conferem a ela a identidade de professora, o que pode ser observado no próximo trecho:

[...] o que me incomodava é que quando ia falar alguma coisa, se eu errasse, ela (supervisora) não esperava e me interrompia. Isso me atrapalhava muito, porque os alunos não me viam como professora, eles viravam e perguntavam para ela [...] Isso me deixou muito mal pelo fato de que, naquele momento, eu não estava sendo professora, os alunos não estavam me vendo como professora (Daniela).

Entretanto, apesar das dificuldades enfrentadas, a situação mudou no Estágio II, quando Daniela relata que dar aula sobre algo que ela tem conhecimento fez toda diferença para que seus alunos a reconhecessem como professora:

Nesse meu segundo estágio, eu dei aulas sobre bactérias, sobre vírus, sobre fungos, então, muitas
coisas que eu aprendi no curso eu levei para lá, tipo, eu lembrei muito das minhas práticas de
Microbiologia quando eu fui dar aula sobre fungos [...] quando eu fui dar aula de doenças em
que os alunos começaram a dizer: "Ah professora, eu conheço tal pessoa que tem esse negócio".
Então [...] isso me fez ver que, de certa forma, eu estava sendo uma professora. Naquele
momento, os alunos: "Professora, eu posso ir ao banheiro?" "professora, eu faltei atividade, eu
posso repor?" Então eles vinham até mim, como professora, me viam como professora
(Daniela).

Esses relatos nos fazem refletir sobre a construção coletiva da identidade, que é marcada pela necessidade do reconhecimento do outro para que seja assumida (DUBAR, 2009). No caso apresentado, a identidade é atribuída mediante o aspecto do domínio do conteúdo; entretanto, é necessário buscar ressignificá-la, na tentativa de evitar uma possível "crise" sobre a identidade do professor. Na sociedade contemporânea, cada dia mais globalizada, em que o acesso à informação se tornou muito mais facilitado, o papel do professor parece se esvaziar. O conhecimento não mais está atrelado à imagem do professor; em uma simples busca pela internet, um universo de informação pode ser obtido. Assim, a profissão que outrora era essencial para esta finalidade parece perder sua importância na sociedade.

De acordo com Libâneo (2001), a identidade profissional emerge do significado pessoal e social atribuído ao professor. Para o autor, "se o professor perde o significado do trabalho tanto para si próprio como para a sociedade, ele perde a identidade com a sua profissão" (LIBÂNEO, 2001, p. 5). Nesse sentido, essa identidade precisa ser ressignificada, passando do aspecto restrito ao domínio do conteúdo para o da mediação entre o conhecimento e os alunos, uma vez que, embora o acesso à 
informação esteja facilitado, ele se dá de forma desigual, e a exposição aos veículos de informação não é garantia para sua aquisição. Além disso, ter informação é diferente de ter conhecimento: a informação constitui apenas um dos estágios do processo de construção do conhecimento. Conhecer implica trabalhar com as informações, classificando-as, analisando-as e contextualizando-as. O papel do professor está, portanto, em auxiliar seus alunos na operacionalização dessas informações, atribuindolhes significados para que, a partir disso, seus alunos possam construir conhecimento e interpretar suas realidades (PIMENTA, 1999).

No que se refere às disciplinas ofertadas pelo curso, os licenciandos ressaltam as disciplinas pedagógicas e de metodologias e práticas de ensino como importantes para o processo de identificação com a profissão. Entretanto, além das contribuições, são apontadas também as limitações de algumas dessas disciplinas que, de certa forma, dificultam o processo de construção da identidade profissional. Um caso recorrente está relacionado às disciplinas denominadas de práticas de ensino. Citadas por todos os participantes da pesquisa, essas disciplinas, na perspectiva dos licenciandos, parecem ter um forte potencial para auxiliar no processo de identificação com a profissão. No entanto, essas disciplinas têm apresentado algumas falhas que dificultam esse processo. Dentre essas falhas, a formação dos professores formadores é apontada pelos licenciandos como um dos principais obstáculos.

A falta de formação específica na área de educação/ensino por parte dos professores formadores reflete na forma como a disciplina é ministrada. Os alunos relatam que alguns professores têm dificuldade em estabelecer as estratégias de ensino e também de avaliação das disciplinas, sempre solicitando o mesmo tipo de atividades, o que, segundo os licenciandos, acaba conferindo às disciplinas um caráter repetitivo, além de, em alguns casos, não terem nexo com a realidade da sala de aula, o que pode ser constatado no trecho seguinte:

Acho que foi muito superficial, eu não consegui ter uma aplicação prática de como eu poderia usar esse conhecimento em sala de aula. Algumas atividades propostas eu não via sentido como prática de ensino, porque pra mim, prática de ensino é o que você vai praticar em sala de aula. [...] "Se vocês estivessem em uma sala de aula, como é que vocês agiriam?" Eles deveriam dar esse tipo de situação. "Se vocês estivessem em uma sala de aula e tal aluno perguntasse isso?" Jogassem situações que a gente realmente vê no ambiente educacional [...] (Samara).

De acordo com Guimarães (2004), as práticas formativas, que constituem as formas como o currículo do curso de licenciatura é desenvolvido, também têm influência no processo de construção da identidade docente dos futuros professores. Segundo o autor, "é num curso de graduação específico e com seus respectivos professores que os alunos estão aprendendo a profissão e têm como referência para construírem sua profissionalidade" (GUIMARÃES, 2004, p. 57). Desse modo, é necessário ressignificar as disciplinas, como as mencionadas nos relatos, com vistas ao desenvolvimento de uma cultura da profissão que, quando interiorizada pelos futuros professores, possa gerar um estilo coletivo de perceber as situações, de pensar os problemas da prática profissional, de encontrar soluções, desenvolvendo competência pedagógica e criando possibilidades para a construção da identidade docente.

Embora o curso e os elementos formativos proporcionados contribuam para que os licenciandos ressignifiquem suas concepções sobre a profissão docente, ao serem questionados sobre sua identificação com a profissão, a maioria das respostas é negativa. Apenas dois licenciandos se identificaram como professores; um deles expressa essa identificação no próximo trecho:

[...] depois dos estágios, depois das práticas de ensino, enfim, eu me sinto como um professor [...] Eu vou sair daqui formado no curso de Ciências Biológicas Licenciatura, com modalidade para ser professor [...] e eu já me considero sim como professor, até porque eu passei pelos estágios, eu tive essa experiência, então lá eles me chamavam como professor, eu era o professor. (Mateus).

No discurso de Mateus, fica evidente a contribuição das práticas de ensino e principalmente a contribuição da experiência proporcionada pelos estágios, na qual, por meio das interações estabelecidas, a identidade de professor é a ele atribuída pelos alunos e posteriormente assumida. Assim 
como no caso de Mateus, Isabel, que também se reconhece como professora, cita os estágios como locus de construção dessa identidade:

\begin{abstract}
O momento que eu entendi que eu era professora de verdade foi no Estágio I, [...] eu percebi que quando você está lá, você está exercendo tudo aquilo que você aprendeu. Tanto da parte de Ciências, quanto da parte da mediação, que eu acho mais legal [...] quando eu percebi que eu era capaz disso, ou então no Estágio II, quando fugiu do controle e tudo bem também fugir do controle e você retomar, nem que seja no dia seguinte. Você entendeu que aconteceram coisas, dá para mudar, não vai ser assim o tempo todo, eu entendi que isso é ser professora e eu super me vejo [...] (Isabel).
\end{abstract}

Notamos que a experiência proporcionada pelos estágios é crucial para a aquisição do sentimento de competência em relação à profissão docente (TARDIF, 2014). Ao perceber que é capaz de mobilizar os saberes que foram construídos ao longo de sua formação para lidar com as situações adversas da profissão, Isabel se assume como professora.

A inserção no ambiente de trabalho, de acordo com Tardif (2014), leva à construção dos saberes experienciais que se transformam em certezas sobre a profissão, em macetes, em modelos de gestão da classe e de ensino da disciplina. Entretanto, esses saberes não se encerram no domínio cognitivo e instrumental do trabalho docente; eles abrangem aspectos como o bem-estar pessoal em trabalhar nessa profissão, a segurança emocional, o sentimento de estar no seu lugar, bem como a confiança nas suas capacidades de enfrentar problemas e de poder resolvê-los. Assim, como vimos em Isabel, o desenvolvimento desses saberes permite que aos poucos a identidade docente seja construída e experimentada em um processo em que entram em jogo elementos emocionais, relacionais e simbólicos que permitem que o indivíduo se considere e viva como professor (TARDIF, 2014).

Percebemos que quando há a dificuldade em desenvolver esses saberes essa identidade tarda em ser assumida. Isso pode ser evidenciado no relato de Bruna, que sente a necessidade de mais experiência no âmbito da sala de aula:

Eu acho que eu estou construindo ainda a minha identidade como professora, sabe? Eu acho que eu preciso de muito mais experiência dentro de sala de aula [...] tenho que estudar muito relações entre as pessoas para a gente saber como entender todo o ambiente de uma sala de aula, porque a gente como professor vai ter que saber lidar com situações que podem acontecer ali. Então, eu acho que eu ainda não tenho isso [...] (Bruna).

Mais uma vez fica evidente a importância de criar possibilidades para o desenvolvimento dos saberes experienciais durante a formação inicial, uma vez que constituem os fundamentos da prática e da competência profissional (TARDIF, 2014), entendida aqui como "a faculdade de mobilizar um conjunto de recursos cognitivos (saberes, capacidades, informações etc.) para solucionar com pertinência e eficácia uma série de situações" (PERRENOUD, 1999, p. 30).

Quando a realidade do futuro ambiente de trabalho é evidenciada somente nos estágios, que em certos casos pode ser insuficiente, a construção desses saberes é afetada e, consequentemente, a identidade docente que eles poderiam conferir. Isso é evidenciado no relato de Samara, que ainda se sente insegura quanto à profissão docente:

[...] não me considero ainda como professora [...] Eu preciso melhorar muito para eu ser professora [...] acho que eu preciso aperfeiçoar mais um pouco a minha didática, a minha oralidade, a minha postura em sala de aula, os meus conhecimentos [...] Se tivesse algum tipo de curso rápido para professores iniciantes eu acho que eu faria, pelo menos pra eu ter mais essa firmeza de chegar na sala de aula e me impor como professora (Samara).

Outro fator que parece dificultar o reconhecimento enquanto profissional docente pelos licenciandos, evidenciado durante o transcorrer desta pesquisa, está relacionado ao fato de que algumas licenciandas desenvolveram o que denominamos de identidade profissional transitória. As licenciandas que manifestaram essa forma de identificação se reconhecem ou desejam ser reconhecidas como 
biólogas, mas não negam a identidade de professora, podendo recorrer a esta última e assumi-la, dependendo das situações e dos contextos que vivenciam:

Eu sou bióloga com habilitação em licenciatura, então se eu quiser dar aula de Biologia eu estou habilitada, eu posso ser professora. Agora se eu quiser trabalhar com outras coisas também que não estão relacionadas à licenciatura, mesmo tendo feito um curso de licenciatura, eu estou apta, pelo menos é isso que diz o Conselho Regional de Biologia" [...] Então, para mim, estar nesse papel de ser professor depende da situação (Luiza).

Essa forma de identificação pode ser explicada tanto pelo caráter mutável da identidade, que pode ser ressignificada constantemente, quanto pelo fato de o próprio curso analisado proporcionar a seus alunos uma identidade profissional híbrida, como apontado por Luiza, conferindo-lhes tanto a identidade de biólogo quanto a identidade de professor. Entretanto, notamos que a identidade de professor parece ficar em segundo plano.

Nesse sentido, ressaltamos a necessidade de revisão da forma como a identidade profissional docente tem sido representada nos cursos de formação inicial, uma vez que este espaço de formação é o locus de construção dessa identidade, e a forma como a instituição e os formadores atuam tem implicações diretas nesse processo (GUIMARÃES, 2004). Desse modo, é necessário um modelo formativo que vá além da formação de "bacharéis que lecionam" e, como discute Tardif (2014), vise uma formação de professores profissionais que, além de apresentarem domínio sobre os conteúdos que lecionam e possuírem conhecimentos didático-pedagógicos, sejam capazes de desenvolver um saber prático baseado na experiência cotidiana e, a cada nova experiência, atribuir novos sentidos a seus saberes, promovendo uma constante formação profissional baseada na reflexão a partir de suas experiências.

\section{CONSIDERAÇÕES FINAIS}

Os resultados aqui apresentados indicam que, proporcionado principalmente pelos Estágios Supervisionados e pelo PIBID, esse contato prévio com o ambiente de trabalho possibilita a construção, mobilização e ressignificação de diferentes saberes ligados à profissão docente, os quais, por sua vez, carregam traços da identidade docente desses licenciandos, auxiliando-os no desenvolvimento de um saber-ser e um saber-fazer pessoais e profissionais validados pela experiência proporcionada por esses espaços.

Dessa forma, ressaltamos a importância de um olhar mais atento aos estágios para que não se desenvolvam como mera atividade burocrática que precisa ser cumprida ou como a parte prática do curso em oposição à teoria. Destacamos o mesmo para o PIBID, que também traz contribuições bastante significativas para a formação dos licenciandos, reforçando mais uma vez a necessidade de considerar o contexto de atuação dos futuros professores, o chão da escola, como espaço formativo, uma vez que pode ser gerador de saberes e consequentemente da identidade docente.

Com base nos resultados obtidos nesta pesquisa, notamos que a identidade profissional dos licenciandos é mutável, construída de forma coletiva; depende do reconhecimento dos alunos para ser assumida e está pautada principalmente em dois saberes: os disciplinares e os experienciais. Entretanto, salientamos a importância da criação de possibilidades para o desenvolvimento dos outros saberes, no sentido de não restringir a profissão docente somente ao domínio da disciplina ou a uma atividade que dependa estritamente da prática para ser desempenhada.

Esperamos que os resultados e reflexões aqui apresentadas possam contribuir para o debate no âmbito da formação de professores e suscitar novos questionamentos e investigações que visem a análise e problematização deste campo de pesquisa, buscando o reconhecimento do professor como profissional dotado de saberes específicos que legitimam sua profissão e, consequentemente, contribuem para sua profissionalização. 


\section{REFERÊNCIAS}

ALARCÃO, Isabel. Reflexão crítica sobre o pensamento de D. Schön e os programas de formação de professores. Revista da Faculdade de Educação da USP, v. 22, n. 2, p. 11-42, 1996. Disponível em: http://www.revistas.usp.br/rfe/article/view/33577. Acesso em: 22 abr. 2019.

BACCON, Ana Lúcia P.; ARRUDA, Sérgio M. Os saberes docentes na formação inicial do professor de Física: elaborando sentidos para o estágio supervisionado. Ciência \& Educação, v. 16, n. 3, p. 507-524, 2010. Disponível em: http://www.scielo.br/pdf/ciedu/v16n3/v16n3a01.pdf. Acesso em: 30 abr. 2019.

BOGDAN, Robert; BIKLEN, Sari K. Qualitative research for education: an introduction to theories and methods. $5^{a}$ ed. Boston: Pearson, 2007.

BRASIL. Pibid - Programa Institucional de Bolsa de Iniciação à Docência. 2019. Disponível em: http://www.capes.gov.br/educacao-basica/capespibid/pibid. Acesso em: 12 jan. 2019.

BRASLAVSKY, Cecilia. Bases, orientaciones y criterios para el diseño de programas de formación de profesores. Revista Iberoamericana de Educación, v. 19, p. 1-28, 1999. Disponível em:

https://rieoei.org/RIE/article/view/1054. Acesso em: 15 maio 2019.

BURIOLLA, Marta A. F. O estágio supervisionado. São Paulo: Cortez, 1995.

CAMPELO, Maria Estela C. H. Alfabetizar crianças - um ofício, múltiplos saberes. Tese (Doutorado). Natal: Universidade Federal do Rio Grande do Norte, 2001.

CARMO, Edinaldo. M.; ROCHA, Winne K. S. A produção dos saberes docentes e o estágio supervisionado: o que dizem as narrativas dos alunos. Revista Inter Ação, v. 41, n. 3, p. 725-742, 19 dez. 2016. Disponível em: https://www.revistas.ufg.br/interacao/article/view/41838. Acesso em: 20 fev. 2019.

CIAMPA, Antonio C. A estória do Severino e a bistória da Severina. São Paulo: Brasiliense, 1987.

CUNHA, Emmanuel R. Os saberes docentes ou saberes dos professores. Revista Cocar, v. 1, n. 2, p. 31 39, 2007. Disponível em: https://paginas.uepa.br/seer/index.php/cocar/article/view/130. Acesso em: 20 fev. 2019.

CUNHA, Maria Isabel. A docência como ação complexa: o papel da didática na formação de professores. In: ROMANOWSKI, Joana P.; MARTINS, Pura L. O.; JUNQUEIRA, Sérgio R. A. (Orgs.). Conhecimento local e conhecimento universal: pesquisa, didática e ação docente. Curitiba: Champagnat, 2004, p. 31-42.

DUBAR, Claude. A Socialização: Construção das Identidades Sociais e Profissionais. Porto: Porto Editora, 1997.

DUBAR, Claude. A Crise das Identidades: a Interpretação de uma Mutação. São Paulo: Editora da Universidade de São Paulo, 2009.

FREIRE, Paulo. Pedagogia da autonomia: Saberes necessários à prática educativa. São Paulo: Editora Paz e Terra, 1996. 
GARCÍA, Carlos M. Como conocen los profesores la materia que enseñan: algunas contribuciones de la investigación sobre conocimiento didáctico del contenido. In: Congreso de las didácticas especificas en la formación del professorado. Santiago de Compostela, 1992, p. 6-10. Disponível em:

http://repositorio.minedu.gob.pe/handle/123456789/3099. Acesso em: 14 mar. 2019.

GAUTHIER, Clermont; MARTINEAU, Stéphane; DESBIENS, Jean-François; MALO, Annie; SIMARD, Denis. Por uma teoria da pedagogia: pesquisas contemporâneas sobre o saber docente. Ijuí: Unijuí, 2013.

GHEDIN, Evandro. Professor reflexivo: da alienação da técnica à autonomia crítica. In: PIMENTA, Selma G.; GHEDIN, Evandro (Orgs.). Professor reflexivo no Brasil gênese e crítica de um conceito. São Paulo: Cortez, 2006. p. 129-150.

GUIMARÃES, Valter S. Formação de professores: saberes, identidade e profissão. Campinas: Papirus, 2004.

HALL, Stuart. A identidade cultural na pós-modernidade. Rio de Janeiro: DP\&A, 2000.

HUBERMAN, Michaël. O ciclo de vida profissional dos professores. In: NÓVOA, Antonio (Org.). Vidas de professores. Porto: Porto, 2007. p. 31-62.

LIBÂNEO, José Carlos. O professor e a construção da sua identidade profissional. In: LIBÂNEO, José Carlos (Org.). Organização e gestão da escola: teoria e prática. Goiânia: Alternativa, 2001. p. 61-72.

LÜDKE Menga; ANDRÉ, Marli E.D.A. Pesquisa em educação: abordagens qualitativas. São Paulo: EPU, 1986.

MARCELO, Carlos. A identidade docente: constantes e desafios. Formação Docente, Belo Horizonte, v. 1, p. 109-131, 2009. Disponível em:

https://revformacaodocente.com.br/index.php/rbpfp/article/view/8. Acesso em: 17 dez. 2018.

MARTINY, Luis E.; SILVA, Pierre N. G. “'O que eu transformaria? Muita coisa!”: os saberes e os não saberes docentes presentes no estágio supervisionado em Educação Física. Revista da Educação Física/UEM, Maringá, v. 22, n. 4, p. 569-581, 2011. Disponível em:

https://www.scielo.br/scielo.php?pid=S1983-30832011000400008\&script=sci_abstract\&tlng=pt. Acesso em: 3 mar. 2019.

MASETTO, Marcos T. Professor universitário: um profissional da educação na atividade docente. In: MASETTO, Marcos T. (Org.). Docência na universidade. Campinas: Papirus, 1998. p. 09-26.

MINAYO, Maria Cecília S. O desafio do conhecimento: pesquisa qualitativa em saúde. São Paulo/Rio de Janeiro: HUCITEC/ABRASCO, 2010.

MOREIRA, Marco Antonio. O professor-pesquisador como instrumento de melhoria do ensino de ciências. Revista Em Aberto, Inep/MEC, v. 40, p. 43-54, 1989. Disponível em:

https://pdfs.semanticscholar.org/c336/fc2e0aeb22d8547eadefa382db53a398e5ee.pdf. Acesso em: 25 jun. 2019.

NUNES, Débora R. P. Teoria, pesquisa e prática em Educação: a formação do professor-pesquisador. Educação e Pesquisa, v. 34, n. 1, p. 97-107, 2008. Disponível em: 
http://www.scielo.br/scielo.php?pid=S151797022008000100007\&script=sci_abstract\&tlng=pt. Acesso em: 7 mar. 2019.

PADILHA, Paulo R. Planejamento dialógico: como construir o projeto político-pedagógico da escola. São Paulo: Cortez, 2001.

PERRENOUD, Philippe. Construir as competências desde a escola. Porto Alegre: Artmed, 1999.

PERRENOUD, Philippe. 10 novas competências para ensinar. Porto Alegre: Artmed, 2000.

PIMENTA, Selma G. Formação de professores: Identidade e saberes da docência. In: PIMENTA, Selma G. (Org.) Saberes pedagógicos e atividade docente. São Paulo: Cortez, 1999. p. 15-34.

PIMENTA, Selma G. Professor reflexivo: construindo uma crítica. In: PIMENTA, Selma G.; GHEDIN, Evandro (Orgs.). Professor reflexivo no Brasil gênese e crítica de um conceito. São Paulo: Cortez, 2006. p. 12-52.

PIMENTA, Selma G.; LIMA, Maria Socorro L. Estágio e Docência. São Paulo: Cortez, 2012.

PONTE, João Pedro; GALVÃO, Cecília; TRIGO-SANTOS, Florbela; OLIVEIRA, Hélia. O início da carreira profissional de professores de Matemática e Ciências. Revista de Educação, v. 10, n. 1, p. 31-45, 2001. Disponível em: https:// repositorio.ul.pt/bitstream/10451/4286/1/01-Ponte-G-S-O(Indu\%c3\%a7\%c3\%a3o-RE).pdf. Acesso em: 15 fev. 2019.

PUENTES, Roberto V.; AQUINO, Orlando F.; QUILLICI, Armindo. Profissionalização dos professores: conhecimentos, saberes e competências necessários à docência. Educar, v. 34, 169-184, 2009. Disponível em: https://www.scielo.br/pdf/er/n34/10.pdf. Acesso em: 3 dez. 2018.

SANTOS, Clara. A construção social do conceito de identidade profissional. Interaç̧ões, v. 8, n. 1, p. 123- 144, 2002. Disponível em: https://www.interacoes-

ismt.com/index.php/revista/article/view/145. Acesso em: 10 nov. 2018.

SCHÖN, Donald. Formar professores como profissionais reflexivos. In: NÓVOA, Antônio (Org.). Os professores e sua formação. Lisboa: Dom Quixote, 1992. p. 77-91.

SHULMAN, Lee S. Those who understand knowledge growth in teaching. Educational Researcher, v. 15, n. 4, p. 4-14, 1986. Disponível em:

http://www.fisica.uniud.it/URDF/masterDidSciUD/materiali/pdf/Shulman_1986.pdf. Acesso em: 26 fev. 2019.

SILVA, Tomaz T. Identidade e diferença: a perspectiva dos estudos culturais. Petrópolis: Vozes, 2007.

TARDIF, Maurice. Saberes docentes e formação profissional. Petrópolis: Vozes, 2014.

Submetido: $12 / 11 / 2020$

Aprovado: 16/08/2021 